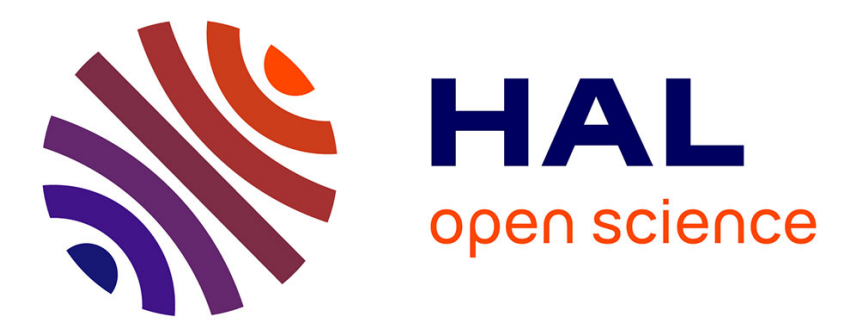

\title{
Designing Game-Based Interventions for Subverting Normative Attitudes
}

\author{
Mikel Polzer, Helmut Hlavacs
}

\section{To cite this version:}

Mikel Polzer, Helmut Hlavacs. Designing Game-Based Interventions for Subverting Normative Attitudes. 16th International Conference on Entertainment Computing (ICEC), Sep 2017, Tsukuba City, Japan. pp.113-124, 10.1007/978-3-319-66715-7_12 . hal-01771301

\section{HAL Id: hal-01771301 \\ https://hal.inria.fr/hal-01771301}

Submitted on 19 Apr 2018

HAL is a multi-disciplinary open access archive for the deposit and dissemination of scientific research documents, whether they are published or not. The documents may come from teaching and research institutions in France or abroad, or from public or private research centers.
L'archive ouverte pluridisciplinaire HAL, est destinée au dépôt et à la diffusion de documents scientifiques de niveau recherche, publiés ou non, émanant des établissements d'enseignement et de recherche français ou étrangers, des laboratoires publics ou privés. 


\title{
Designing Game-Based Interventions for Subverting Normative Attitudes
}

\author{
Mikel Polzer and Helmut Hlavacs* \\ University of Vienna, Faculty of Computer Science, \\ Entertainment Computing Research Group \\ Vienna, Austria \\ m.polzer@gmx.net, helmut.hlavacs@univie.ac.at
}

\begin{abstract}
The present study explores persuasive and interventional strategies for designing and evaluating low-threshold browser games that adequately aim for affording prejudice-reducing social impact in everyday life scenarios. Our investigation was guided by the premise that a covert persuasion approach is suited for also reaching out to otherwise adverse attitude holders. Building on a framework for embedding change-related messages into games by their design, and in combination with rhetorical techniques and subversive strategies from queer-theoretical philosophy and social psychology, we modified an existing impactful game about Coming Out so as to obfuscate its change-related content, and make it more approachable for a not-queer audience. The evaluation of the modified prototype suggests the efficacy of the employed strategies for facilitating and elevating emotional engagement based on group membership effects, which is linked to a greater potential for attitude change and prejudice reduction.
\end{abstract}

Keywords: Social impact games · Prejudice reduction - Embedded persuasion · Activist games - Queer game design

\section{Introduction}

\subsection{Background}

As digital technologies are becoming increasingly advanced, available and affordable around the globe [1], digital entertainment systems are gaining popularity and prevalence among a variety of users, too. Correspondingly, the rising consumption of entertainment media has increased their "significant role as socializing agents" [2] especially that of digital games, which are superseding non-interactive media [3]. Aside from these quantitative aspects, another indicator for the social impact of games results from the unique quality of their consumption, especially in the light of unprecedented technological possibilities for social interaction, self-representation and identity (re-)construction [4]. On the one hand, character-based online gameplay scenarios are a showcase for the transference of persisting social norms into virtual environments. On the other hand, these environments seem to enable counter-normative behavior, as seen in 
the phenomenon of online gender-swapping (assigning a different gender identity to ones online avatar than ones 'offline' gender) [5]. From a queer-theoretical point of view, these acts can be said to constitute a performative transgression of the conceptual boundaries that regulate and maintain one of the most fundamental social categories: in 'real life', perceived deviations from norms regarding gender and sexuality face societal repression [6], as do individuals based on categorizations by 'race' or 'ability'. Such sanctions can be directly or implicitly enacted in the form of hostile and aversive attitudes towards non-conforming individuals, frequently expressed subtly in everyday interaction [7].

\subsection{Motivation}

Considering the prevalence and persistence of normative attitudes, these emergent trends emphasize the social dimension of games and the responsibility for their design: games seem to bear the potential to reinforce, but also to transform social normativity and the structures of inequality resulting from it. These possibilities and challenges have motivated the development of "serious games for social change" [8], which exploit the cognitive and affective affordances of gameplay for pro-social persuasive purposes, such as prejudice reduction and prosocial attitude change. While many game-based interventional systems have been successfully deployed, research on their systematic design is still in its early stages. For one thing, many of these games were developed outside an academic context and hence without a scientific framing. On the other hand, as has been noted by G. Kaufman and M. Flanagan [9], much work relies on an explicit persuasive strategy that focuses on providing propositional information and factual content. However, as has been shown by research on social cognition and psychology, overt persuasive approaches often run the risk to fail especially in the context of prejudice reduction, where a high perception of psychological threat and the resulting activation of defense mechanisms are often encountered. More-over, an educational appeal might impair the quality of gameplay, and consequently reduce its interventional efficacy or transformative impact. In addition, overt approaches are methodologically problematic in the context of attitude assessment and thus for the evaluation of social intervention games. For these reasons, this work focuses on the investigation of subtle design and evaluation strategies for implementing the premise that "serious games must look like casual games" [10]. Extending the Embedded Design Model developed by G. Kaufman, M. Flanagan and M. Seidman [11] with additional persuasive strategies on the basis of queer theory and digital gameplay affordances, we argue, is suitable for addressing subtle manifestations of internalized norms related to gender, sexuality, race and related social group concepts that manifest as daily prejudiced and stereotyped attitudes. 


\section{Attitude Persistence and Change}

\subsection{Attitudes}

In basic terms, an attitude is "an evaluation of an object of thought", i.e. of the mental representations of "things, people, groups, and ideas" [12]. This evaluative mechanism plays a crucial role in regulating the dynamics within interactive systems: on the basis of an attitudes positive or negative valence, individuals will decide which entities to avoid, and which objects to approach or engage with [13]. According to dual-processing theories, attitudes are formed based on propositional and associative learning processes. Similarly, their adaptation is typically induced by the acquisition of novel information about the attitude object, e.g. due to new significant encounters with representatives of a concept, which revise the validity of previous beliefs about and/or emotions towards it.

\subsection{Prejudice and Stereotype}

Prejudiced and stereotypical attitudes are negative evaluations that are formed prior to actual encounters or reasoning, and instead based on societal norms about concepts referring to social groups [14]. Despite their fallacious cognitive structure and unjustified affective nature, stereotype and prejudice are particularly resistant against modification through learning. Researchers have attributed this persistence to a strong association of normative beliefs with ones central self-concept and worldviews [15]. Therefore, any transformative attempt be-comes fundamentally psychologically threatening, which further triggers a number of defensive resistance mechanisms to prevent relevant normative attitudes from being updated. In the context of designing prejudice-reducing interventional games, the consideration and circumvention of such mechanisms thus poses a core challenge.

\subsection{Resistance Mechanisms}

Avoidance and Selective Exposure. The principle of avoidance strategies is simple: the recipient prevents her/his/their attitudes from being updated by evading any exposure to counter-attitudinal information [16], i.e. information that would presumably force her/him/them to modify beliefs or feelings about or towards a topic, group or (other) ideological constructs. Such behavior has also been linked to aversive racism [17], a form of internalized racist prejudice which leads to the unconscious avoidance of certain social groups. Moreover, the attitude holder is mostly unaware of their prejudice, which makes it even more difficult to address. In the context of the present work, avoidant behavior could prevent potential recipients from playing a game if it is perceived to contain a counter-attitudinal message. In the case of strong prejudice, knowing that the game features prejudice-targeted social group member(s) might even be sufficiently repellent. This effect was prevented by applying the obfuscation strategy. 
Reactance. The phenomenon of reactance results when an individual feels forced to preserve their freedom and independence in view of a persuasive attempt [18]. Moreover, this effect even occurs when the attitude holder actually agrees with the position or message transported in the course of the persuasion. Therefore, this effect is another instance that was considered in the present context, by refraining from any persuasive appeals when framing the game. It was therefore not framed as a game with a different interventional target.

\section{Related Work}

\subsection{Embedded Design Model}

In view of these psychological responses, G. Kaufman, M. Flanagan and M. Seidman have developed a general model for covertly embedding change-related messages into interventional games for prosocial attitude shifts. This framework offers broad guidelines that are applicable to a variety of different game genres, including digital, character-based interactive fiction. The model specifies three guidelines, for which the authors provide example techniques regarding their implementation.

Intermixing. This technique consists in balancing 'on-message' and 'off-message' content, whereas the developers suggest that an unbalanced ratio with less onmessage content leads to more transformative impact than a reversed ratio of overloaded message-content.

Obfuscating. The obfuscation strategy consists in diverting the players attention away from the games persuasive intention, by employing genre, framing language or similar devices for distraction. One variant of this technique consists in the gradual introduction of message-related content: in non-interactive fiction, for example, the delayed revelation of a characters outgroup membership has been linked to higher effects of experience-taking, which enable the reduction of outgroup bias.

Distancing. This principle seeks to provide a sufficient degree of safety so as to allow for a transgression of normative boundaries despite their association with ones self-concept. Consequently, this is done by increasing the "psychological gap" be-tween in-game experience and 'real-life', thereby allowing for the players narrative transportation and emotional engagement [19]. This can be achieved by employing fiction and metaphor, and the suggestion of hypotheticality.

These techniques have been successfully tested and applied to non-digital multi-player games of party-game genres by the developers. Despite suggestions, the model itself does not contain any detailed specifications regarding the mes-sage-unrelated content (for the intermixing strategy), genre choices (for 
the obfuscating strategy), or the narratological introduction of a characters outgroup membership (for the distancing strategy). These were added on the basis of further persuasive strategies and in consideration of the defense effects that normative attitudes are accompanied by.

\subsection{Performativity and Embodied Persuasion}

Procedural Rhetoric. The notion of procedural rhetoric, as suggested by I. Bogost [20], refers to the "practice of persuading through processes", especially those of computational nature. As an argumentative practice, it is helpful for both the designer and the player, as suggested by the author. Games, by virtue of their "procedurality" and interactivity, afford the employment of arguments in a procedural way, e.g. the embodiment of ideologies and normativity, and the revelation of the dynamics they result in. As such, games can function as an analogy, or even as a parody.

Parody as Subversive Strategy. The argumentative power and function of embodied imitation has also been analyzed in the context of societal norms and the possibility their transformation. As expressed by philosopher J. Butler: "In imitating gender, drag implicitly reveals the imitative structure of gender itselfas well as its contingency." [21]. In this sense, gender swapping, as facilitated in digital games, might work to implicitly subvert gender norms and related ideologies.

\subsection{Psychotherapy-informed Prejudice Reduction}

As noted by M. Birtel and R. Crisp [22], the cognitive and affective biases that characterize stereotype and prejudice show phenomenological similarities to symptoms of pathological anxiety, e.g. patterns of distorted thinking and irrational fear. This has motivated the employment of techniques adopted from cognitive-behavioral therapy for the purpose of prejudice-reduction. One of the adopted strategies builds on the principle of exposure therapy, in which a patient is confronted with an instance of the feared concept in order to reduce anxiety and distress triggered by it. [23] This intervention requires a sufficiently safe and unthreatening environment or framing, which can be achieved by mentally simulating an encounter.

Imagined Intergroup Contact. As has been theorized by G. W. Allport [24], meaningful intergroup contact can effectively reduce prejudiced attitudes towards social groups. In order to evade potentially adverse effects related to persuasive pressure, the technique of imagined intergroup contact [25] relies on the safe affordances and therapeutic effects of mental simulation for prejudice reduction. The successful deployment of this interventional strategy suggests a promising efficacy when combined with the engaging, interactive and yet fictional, 'casual' appeal of gameplay. 


\section{Design and Implementation}

Based on these assumptions, the Embedded Design Model was extended and applied for the modification of an existing social impact game, which was targeted for a queer or queer-friendly audience and did therefore not rely on a covert strategy, with the goal to conceal its interventional attempt while preserving its prosocial message.

\subsection{Original Game}

The open-source browser game Coming Out Simulator developed by game designer N. Case [26] is a semi-autobiographic dialogue-based fiction about a queer game developer's coming out experience. The protagonist Nick appears as nonplayer character in the first scene, and becomes playable as the user jumps into Nicks simulator in order to interactively experience the story from first-person perspective. The player interacts with the system by making choices among several answers and action options. The story has different endings, and the user is given the freedom to make the crucial choice whether to come out to the parents as gay/bisexual or stay 'closeted'. In the end, the user returns, talking to the NPC-version of Nick again (see Figure 1).

Game Principles and Mechanics. Since the game is framed as a story, it does not specify a goal or score metrics there are no 'right' or 'wrong' answers. This is a crucial part of the games em-bodied rhetoric: the system does not correct the player. While this is a beneficial aspect e.g. with regard to the aforementioned backfiring effect, it also poses a difficulty when re-framing the game in the sense of the Obfuscation strategy defined by the Embedded Design Model.

Narratological Design and Structure. The games conceptualization as 'story within a story' interestingly embodies a sort of pathway for narrative transportation: by introducing another layer of hypotheticality, the game suggests a further step away from 'real-life', in the sense of the Distancing strategy described in the Embedded Design Model. In addition, the shift of narrative perspective along with the concept of 'simulation' encourages experience-taking. Furthermore, the games slogan 'a half-true story about half-truths' can be viewed as an ironic handling of the contradiction between telling a story and playing a game which changes the story, as faced in the con-text of interactive fiction writing. At the same time, it can be interpreted as a critical commentary on essentialist constructions of heteronormative ideologies and the fallacies of stereotype and prejudice.

Graphical Design and Interface. The graphical interface, which reminds of text messaging applications, supports the games focus on dialogue and communication. The cartoonish style further-more facilitates an innocent and casual appeal, which works in the sense of Distancing again. 


\subsection{Modification}

The modification attempted to retain the beneficial aspects the original game design affords, on the premise that these didnt reveal the message beforehand. The game mechanics and graphical interface were therefore kept. The narratological structure was employed as well, with one exception: this game version does not feature multiple endings, but 'forces' the user to come out to the parents. This design choice was made with regard to the evaluation, for the sake of comparability. On the other hand, it embodies the lack of power to escape or correct unjustified prejudice, which is also the case for some choices in the original game and makes up an important part of the procedural rhetoric of the game. The greatest change was made to the content and framing of the story, both of which in the case of the original game intentionally reveal its purpose before-hand. In order to refrain from giving it a moralizing tone, the game was not re-designed as a puzzle or learning game which wouldve included an instance for the correction of 'wrong' answers or choices made by the player. Also, the presence of a controlling and evaluating dimension might have impacted the players ability for experience-taking and narrative transportation. For these reasons, the game was framed as a message-driven interactive story; however, not in an activist and topic-related, but in a 'personal' and thus less threatening sense.

Target Audience. The modified version is designed for a non-queer (heterosexual) audience which might have moderately explicit or implicit prejudiced attitudes towards queer (not heterosexual) individuals or topics. However, the persuasive effects are expected to be highest in players who share salient characteristics with the protagonist that are of significance with regard to the conflicts. In this version of the game, those features are the characters educational background and, as in the original game, the characters sexual orientation. In this work, we were most interested in players who shared the first group membership with the character, but not the second.

Synopsis. The interactive fiction, titled The Imitation Game, is framed as a metaphorical story about a difficult day in the life of a computer-science student, on which he faces two situations of stereotype-based rejection. The first conflict occurs at a job interview, based on the interviewers stereotypical belief that computer geeks are the opposite of 'creative'. The conflict is followed by the characters coming out as gay to the parents, for which he is rejected following the same logic of prejudice. Before returning, the player makes one last positive encounter with an NPC. His little brother asks him for help with his computerscience homework.

Narratological Structure. The structure of the game was retained: the player has an encounter with the NPC, who then becomes playable, however with a different motivation: instead of offering the player to experience a simulation, the NPC asks the player to help them (re-)write their story in real-time. The 
player now has the chance (the task) to create a 'true' story about the NPC, even if it is not the story others might like to hear .

Persuasive Effects. The game relies on appeals to empathy, sympathy and identification effects due to ingroup bias, which hypothetically also affect experiencetaking and narrative transportation in players who identify with the protagonists initially revealed group membership (computer science students, game designers, geeks, gamers). The first conflict, in which the antagonistic NPC invokes negative stereotypes towards this group, should generate more emotional engagement in players who identify with this group. If this effect is strong enough, it should maintain those players engagement also in the following scene and conflict, where the characters outgroup membership (gay, bisexual, queer) is revealed. In this sense, the order of the events serves in the sense of an affective strategy of persuasion, and polarizes the players attitudes. Moreover, this procedural aspect also embodies a propositional argument: the first conflict has the same fallacious structure as the second one. Hence, it serves as an analogy that reveals the flaws of prejudiced logic. This forces a player to reach the same conclusions in the second conflict as in the first conflict, also on a level of affect. If a player felt a sense of injustice and anger in the first case, these implicit evaluations should also hold for the second case. The positive encounter in the last scene is meant to reinvoke and appeal to the first group membership (ingroup bias) again, and to procedurally implicate and encourage a similar positive and affirmative reaction towards members from the second group. As the player returns, and the PC becomes an NPC again, the player both had an imaginary encounter with and also took the perspective of an out-group member (regarding the second group concept) (see Figure 2).

\section{Evaluation}

We implemented a semi-quantitative study for in-game and post-game subjective assessment of gameplay experience. Participants were asked to test-play the prototype game and report their experiences qualitatively (providing answers to open-ended questions) as well as quantitatively (indicating their level of agreement with subjective statements on a 7 -point Likert scale). These reports were obtained in written form, for which a questionnaire was used.

\subsection{Experimental Setup}

Participants. The study was conducted with 10 participants, 8 of them male, all of which were between 23 and 28 year-old university students. Each participant completed the test individually and voluntarily after written consent was obtained. The study was conducted in a controlled environment, using the same infrastructure and prototype version of the game. In order to facilitate mental involvement, participants were made aware that the study did not depend on psychometric measures or other objective performance (e.g. reaction time, 


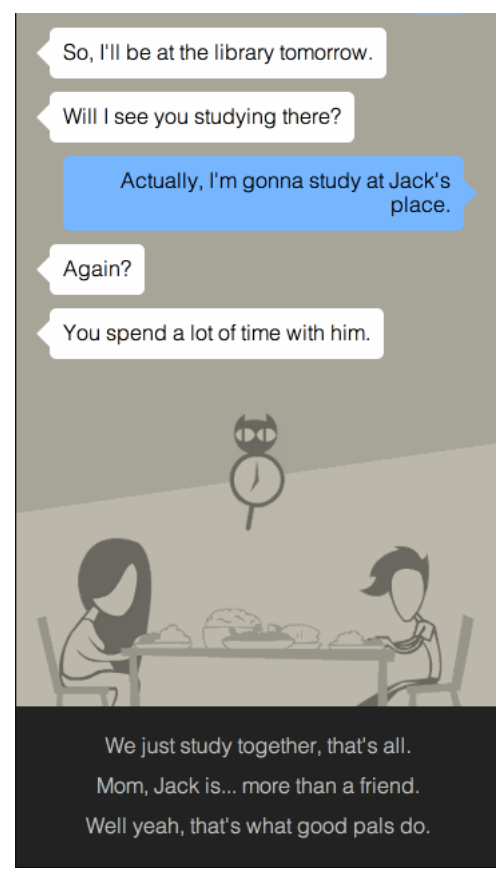

Fig. 1. Screenshot of the original game's coming out scene.

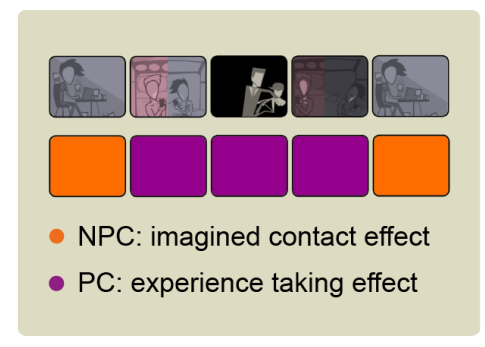

Fig. 2. Storyboard and effects related to narrative perspective.

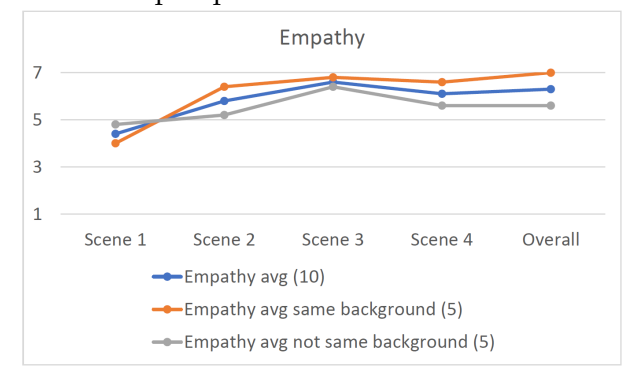

Fig. 3. Levels of empathy reported in and post gameplay.

reading speed or similar), but relied on experiential data subjectively reported by them only. Each run-through had a duration of about 30-40 minutes (2025 minutes for gameplay and 10-15 minutes for completing the questionnaire). The questionnaire used for obtaining subjective data consisted of two parts: one for in-game evaluation, and one for post-game evaluation as well as obtaining demographic data.

Part I - In-Game. Part one consisted of a series of three scales ranging from 1 (low) to 7 (high), indicating the level of empathy, sympathy, and of identification, respectively, that the participant had felt towards the main character Nick during gameplay. This series was answered immediately at the end of each scene (except for the last scene, where the second part of the questionnaire was provided).

Part II - Post-game. The same scales were used once again after gameplay, to indicate the overall levels of felt empathy, sympathy and identification, referring to the gameplay experience in general. Additionally, participants were asked to report their levels of narrative transportation using the 6-item narrative transportation scale, short form [27]. In order to assess whether the game was perceived as an educational, interventional or persuasive game, participants 
were asked to describe what the game was about in an open-ended question. Demographic and/or personal data was partly obtained indirectly, by asking participants to indicate which (perceived) demographic characteristics they share with the character. Other questions regarded interaction possibilities, technical/functional aspects of the game-play experience, as well as feedback regarding the game and the evaluation itself.
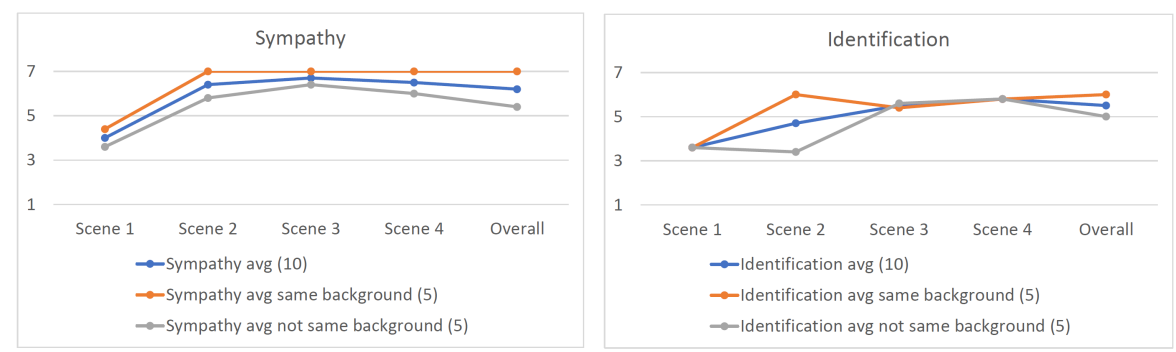

Fig. 4. Levels of sympathy and identification reported in and post gameplay.

Results. The obtained data was analyzed by grouping participants based on their indication of perceived similarity to the character with regards to five characteristics: educational/professional background/study field, age, gender, sexual orientation/sexuality, and interest in gaming/computer games. We were especially interested in the impact a perceived shared educational/professional background and/or interest in computer games has on the levels of empathy, sympathy and identification felt towards the character during each scene (scene 1 scene 4) and overall. Narrative transportation levels on average were higher for same-background individuals as compared to not-same background individuals. Results are seen in Figures 3 and 4.

\section{Discussion}

The experimental results suggest the occurrence of ingroup bias effects with correspondingly elevated levels of sympathy, empathy and identification report-ed during the introductory scene and first conflict by members who share the group membership (computer-related background) that was made salient there. Empathy and sympathy levels continue to be elevated in the second conflict even if players didnt share the group membership (queer sexual orientation) that was made salient at this point of the interactive fiction. More importantly, the levels for all three items raised after gameplay, as reflected in the overall evaluation of the game. An interesting observation was made regarding the identification of and with the characters study field (background): two participants ascribed a different background to the main character than the rest, namely the one they 
each identified with. This suggests a potential inclination and flexibility in the perception of characteristics that could be exploited when designing games for a large audience. Character design could aim at ambiguity in order to be appealing for different, maybe even contradictory reasons. None of the participants answers regarding the game itself indicated that they perceived the game as an educational, interventional or social change game, while all participants were aware of the characters sexual orientation, and experienced the conflict related to it with high levels of empathy and sympathy towards the character during their coming out. This suggests the successful implementation of an embedded design and evaluation strategy.

\section{Conclusion}

This exploratory study demonstrates a possible application of the general guidelines offered by the Embedded Design Model, combined with prejudice-reduction techniques, to the design of small-scale character-based games. The findings are rather to be regarded as a stepping stone for further research and iteration - both on the level of design and implementation. Probably the greatest shortcoming the current design strategy poses, lies in the conditionality of its efficacy, which requires the message to stay hidden to the users until they 'play' it. This poses a limitation to a games' (re-)usability, especially for activist purposes that seek to reach a wide audience. Also, its effect is currently restricted to one gameplay session. This aspect could be refined with the aid of narratological devices such as cliffhanger situations [28]. These techniques could motivate further confrontation with the game and topic once the player is involved, and thereby enhance the games efficacy and impact.

\section{References}

1. International Telecommunication Union (ITU), "Measuring the Information Society (MIS) Report," 2015. Available at http://www.itu.int/pub/D-IND-ICTOI2015.

2. S. Prot, C. A. Anderson, D. A. Gentile, W. Warburton, M. Saleem, C. L. Groves, and S. C. Brown, "Media as agents of socialization," in Handbook of Socialization (J. Grusec and P. D. Hastings, eds.), pp. 276-300, NY: Guilford Press, 2015.

3. Entertainment Software Association (ESA), "Essential Facts About The Computer And Video Game Industry," 2016. Available at http://essentialfacts.theesa.com.

4. L. Nakamura, "Race In/For Cyberspace: Identity Tourism and Racial Passing on the Internet," in Reading Digital Culture (D. Trend, ed.), pp. 226-235, Malden, MA: Blackwell, 2001.

5. Z. Hussain and M. D. Griffiths, "Gender swapping and socializing in cyberspace: An exploratory study," CyberPsychology \& Behavior, vol. 11, pp. 47-53, feb 2008.

6. J. K. Bosson, J. N. Taylor, and J. L. Prewitt-Freilino, "Gender role violations and identity misclassification: The roles of audience and actor variables," Sex Roles, vol. 55, pp. 13-24, nov 2006. 
7. S. A. Chambers, "'an incalculable effect': Subversions of heteronormativity," Political Studies, vol. 55, pp. 656-679, oct 2007.

8. C. Klimmt, "Serious Games and Social Change. Why They (Should) Work," in Serious Games: Effects and Mechanisms (U. Ritterfeld, ed.), pp. 247-270, NY: Routledge, 2009.

9. G. Kaufman and M. Flanagan, "A psychologically "embedded" approach to designing games for prosocial causes," Cyberpsychology: Journal of Psychosocial Research on Cyberspace, vol. 9, no. 3, 2015.

10. H. Hlavacs, "Serious games must look like casual games," in Entertainment in Serious Games and Entertaining Serious Purposes Workshop at ICEC2014, (Sydney, Australia), Sept. 2014.

11. K. Geoff, F. Mary, and S. Max, "Creating stealth game interventions for attitude and behavior change: An \&ldquoembedded design\&rdquo model," Diversity of play: Games Cultures Identities, vol. 2, no. 3, pp. 173-193, 2016.

12. G. Bohner and N. Dickel, "Attitudes and attitude change," Annual Review of Psychology, vol. 62, pp. 391-417, jan 2011.

13. G. Bodenhausen and B. Gawronski, Attitude Change, pp. 957-969. Oxford Unversity Press, 2013.

14. R. Brown, Prejudice: Its Social Psychology. Wiley-Blackwell, 2010.

15. A. G. Greenwald, M. R. Banaji, L. A. Rudman, S. D. Farnham, B. A. Nosek, and D. S. Mellott, "A unified theory of implicit attitudes, stereotypes, self-esteem, and self-concept," Psychological Review, vol. 109, no. 1, pp. 3-25, 2002.

16. D. Frey, "Recent research on selective exposure to information," in Advances in Experimental Social Psychology, pp. 41-80, Elsevier BV, 1986.

17. J. F. Dovidio, Prejudice, Discrimination, and Racism. Academic Press, 1986.

18. J. W. Brehm, "Control, its loss, and psychological reactance," in Control Motivation and Social Cognition, pp. 3-30, Springer Nature, 1993.

19. M. C. Green and T. C. Brock, "The role of transportation in the persuasiveness of public narratives.," Journal of Personality and Social Psychology, vol. 79, no. 5, pp. 701-721, 2000.

20. I. Bogost, Persuasive Games: The Expressive Power of Videogames (MIT Press). The MIT Press, 2007.

21. J. Butler, Gender Trouble. Routledge Press, 1999.

22. M. D. Birtel and R. J. Crisp, "Psychotherapy and social change: Utilizing principles of cognitive-behavioral therapy to help develop new prejudice-reduction interventions," Frontiers in Psychology, vol. 6, nov 2015.

23. R. N. Turner, M. Hewstone, and A. Voci, "Reducing explicit and implicit outgroup prejudice via direct and extended contact: The mediating role of self-disclosure and intergroup anxiety.," Journal of Personality and Social Psychology, vol. 93, no. 3, pp. 369-388, 2007.

24. G. W. Allport, The Nature of Prejudice. Doubleday Anchor, 1958.

25. S. Stathi, K. Tsantila, and R. J. Crisp, "Imagining intergroup contact can combat mental health stigma by reducing anxiety, avoidance and negative stereotyping," The Journal of Social Psychology, vol. 152, pp. 746-757, nov 2012.

26. N. Case, "Coming Out Simulator," 2014. Available At: ncase.me.

27. M. Appel, T. Gnambs, T. Richter, and M. C. Green, "The transportation scale-short form (TS-SF)," Media Psychology, vol. 18, pp. 243-266, feb 2015.

28. A. Lugmayr, E. S. J. Suhonen, C. I. Sendano, and H. Hlavacs, "Serious Storytelling and Serious Entertainment - A Survey and Definition," 2017. accepted by Multimedia Tools and Applications. 